\title{
Influence of Exchange Rate on BSE Sensex \& NSE Nifty
}

\author{
*Aruna Polisetty, ** Dr. D.Prasanna Kumar, *** Mrs.Jikku Susan Kurian \\ *Asst.Prof.Klubs, Kluniversity, \\ **Asso.Prof, Klubs, Kluniversity \\ *** Asst.Prof, Klubs, Kluniversity
}

\begin{abstract}
Predicting currency movements is perhaps one of the hardest exercises in economics as it has many variables affecting its market movement. The changes in the capital market bring transformation in the entire economy of the country. The boom and depression of the capital market are reflected in all sectors of the economy. The foreign exchange market and the stock market are vital for any well-defined financial system of a country. Stock price downward movement continuously in the market forewarns the crisis period in advance. This study analyses the dynamic relationship between stock market and exchange rate and explores the long-run and short-run causal relationship between the stock market and the exchange rate in India for the major decade 2005-2014 of indices BSE Sensex and Nifty NSE. As US Dollar is a prominent currency for foreign trade, the exchange rate of rupee and US Dollar has been taken for the study. BSE Sensex NSE NIFTY index is a bench marking index that is used to measure the economic development of a country like India. The present study conducted from 2005-2014 for a period of 10 years. Correlation between NSE NIFTY, BSE SENSEX with reference to Exchange Rates can be calculated. This explains about the relationship between the variables
\end{abstract}

Keywords: Stock Market, Foreign Exchange, BSE SENSEX, NSE NIFTY, Correlation.

\section{Introduction}

Globalization and financial liberalization in India have brought about a lot of changes in the financial functioning of the economy, as a result of which, the resultant gain of the global integration of domestic and foreign financial markets has thrown openly new opportunities but at the same time exposed the financial system to significant risks. The gradual abolition of foreign exchange controls in emerging economies like India has opened the possibility of international investment and portfolio diversification. At the same time, the adoption of more flexible exchange rate regimes by these countries in the late 1980's and early 1990's has increased the volatility of foreign exchange markets and the risk associated with such investments.

The advent of floating exchange rates, opening up of current account, Liberalization of capital account, reduction of customs duties, the development of 24-hour screen based global trading, the increased use of national currencies outside the country of issue and innovations in Internationally traded financial products have led to the cross country linkages of capital markets and international integration of domestic economy. The process of economic liberalization and thrust on reforms in the financial sector and the foreign exchange market in particular that was initiated in India in early nineties has resulted into increasing integration of the Indian FX market with that of the global markets. With a large number of foreign funds and foreign institutional investors now actively participating in the Indian financial markets, the style of functioning of the market itself has undergone a lot of change and result of microstructure changes are visible. Today the Indian FX market, which was insulated from outside impacts, has been getting integrated with the world markets.

An exchange rate has two effects on stock prices, a direct effect through multi-national Firms and an indirect effect through domestic firms. In case of multi-national Firms involved in exports, a change in rate will change the demand of its product in the international market, which ultimately reflects in its $\mathrm{B} / \mathrm{S}$ as profit or loss. Once the profit or loss is declared, the stock price will also change for a domestic firm. On the other hand, currency devaluation could either raise or decrease a firm's stock prices. This depends on the nature of the firm's operations. A domestic firm that exports part of its output will benefit directly from devaluation due to an increase in demand for its output. As higher sales result in higher profits, local currency devaluation will cause firm stock price to rise in general. On the other hand, if the firm is a user of imported inputs, currency devaluation will raise cost and lower profits. Thus, it will decrease the firm's stock price.

\section{Significance of the Study}

The determination of relationship between the foreign exchange market and stock market would help the researchers to increase their understanding about these markets. It would also provide a platform for participants to enhance their views about the relationship between the two markets. 


\section{Scope of the Study}

The study includes only one currency pair i.e. INR/USD for the representation of the FOREX market while the two major stock markets of India are covered. Thus the relation and effects of other currencies is out of the preview of the research.

\section{Limitations \\ $>$ Un Availability of intra-day minute to minute data of both the markets. \\ $>$ The research is limited to period of ten years. \\ $>$ Only one pair of USD/INR is used.}

\section{Literature Review}

Wu (2000) did a study using stock prices and exchange rates of Singapore and portrayed a unidirectional causality from exchange rates to stock prices. Yamini Karmarkar and G Kawadia tried to investigate the relationship between RS/ exchange rate and Indian stock markets. Five composite indices and five sectoral indices were studied over the period of one year: 2000. The results indicated that exchange rate has high correlation with the movement of stock markets. Apte (2001) investigated the relationship between the volatility of the stock market and the nominal exchange rate of India by using the EGARCH specifications on the daily closing USD/INR exchange rate, BSE 30(SENSEX) and NSE 50(NIFTY) over the period from 1991 to 2000. The study suggest that there appears to be a spillover from the foreign exchange market to the stock market but not the reverse. In a recent study Bhattacharya and Mukherjee (2003) investigated Indian markets using the data on stock prices and macroeconomic aggregates in the foreign sector including exchange rate concluded that there is no significant relationship between stock prices and the exchange rates.

To examine the dynamic linkages between the foreign exchange and stock markets for India, Nath and Samanta (2003) employed the Granger causality test on daily data during the period March 1993 to December 2002. The empirical findings of the study suggest that these two markets did not have any causal relationship. When the study extended its analysis to verify if liberalization in both the markets brought them together, it found no significant causal relationship between the exchange rate and stock price movements, except for the years 1993, 2001 and 2002 during when a unidirectional causal influence from stock index return to return in forex market is detected and a very mild causal influence in the reverse direction is found in some years such as 1997 and 2002.

Muhammad and Rasheed (2003) examined the relationship between stock prices and exchange rates of four South Asian countries named as Bangladesh, India, Pakistan and Srilanka and found that there is no significant relationship between the variables either in short-run or longrun in Pakistan and India.

Razvan and stefanescu and Ramona Dumitriu (2013) explored that the influence of the foreign exchange rates variations on the returns and volatility of the stock prices from the Romanian capital market for the period of the January 2000-December 2012.It is concluded that influence of foreign exchange rates variation on the returns depend on various factors like capital inflows, the global crisis effects the perceptions of the national economy.

\section{Methodology}

For the purpose of study the secondary data collected from the official websites of BSE, NSE and also Exchange Rate data from www.exchangerate.com.

\section{Research Problem}

In the last two decades, globalization, inter linkages of the capital markets, gradual eradication of capital inflow barriers and the implementation of more flexible exchange rate mechanism in developed as well as transition economies, created a systematic interdependency between and within the stock and foreign exchange markets. The people do not have any idea about such relationship between two markets. Thus, investigating the relationship between stock prices and exchange rates has an important factor for the investors to invest their investment in the stock market. The investor's perception may be changing whenever the exchange rates changes frequently changed.

\section{Objectives of the Study}

The major Intention to conduct this study is

1. To investigate the relationship between the foreign exchange market and stock market in India. To see that weather there is a significant relationship and linkage between the two markets.

2. To know how fast one market reflects new information from the other. If relation between foreign exchange market and stock market exist, how the investor use this information to predict the exchange rate movement or the indices movement. 
Hypothesis- Make statement(s) regarding unknown population parameter values based on sample data Elements of a hypothesis test:

Null Hypothesis - Statement regarding the value(s) of unknown parameter(s). Typically will imply no association between explanatory and response variables in our applications (will always contain an equality)

Alternative Hypothesis - Statement contradictory to the null hypothesis (will always contain an inequality)

Test Statistic - Quantity based on sample data and null hypothesis used to test between null and alternative hypotheses

Null Hypothesis (H0): There is no significant relation between stock prices and exchange rates

Alternative Hypothesis (H1): There is significant relation between stock prices and exchange rates

\section{Data Analysis}

Data Collection Data is collected for Indian stock indices (BSE \& NSE) and the INR-USD exchange rate from 1st April 2005 to 31st March 2014. Daily observations of BSE \& NSE and the INR-US dollar exchange rate were gathered from historical data section of www.nseindia.com, www.bseindia.com and www.onada.com.

\section{Correlation}

Correlation is a statistical technique that can show whether and how strongly pairs of variables are related. In general, $r>0$ indicates positive relationship, $r<0$ indicates negative relationship while $r=0$ indicates no relationship (or that the variables are independent and not related). Here $r=+1.0$ describes a perfect positive correlation and $\mathrm{r}=-1.0$ describes a perfect negative correlation. Closer the coefficients are to +1.0 and -1.0 , greater is the strength of the relationship between the Variables. As a rule of thumb, the following guidelines on strength of relationship are often useful.

\begin{tabular}{|c|c|}
\hline Value of $\mathbf{r}$ & Strength of relationship \\
\hline-1.0 to -0.5 or 1.0 to 0.5 & Strong \\
\hline-0.5 to -0.3 or 0.3 to 0.5 & Moderate \\
\hline-0.3 to -0.1 or 0.1 to 0.3 & Weak \\
\hline-0.1 to 0.1 & None or very weak \\
\hline
\end{tabular}

Correlation is appropriate for examining the relationship between meaningful quantifiable data (e.g. air pressure, temperature) rather than categorical data such as gender, favorite color etc.

Table No. 1: BSE- Sensex and Exchange-Rate

\begin{tabular}{|c|c|c|c|}
\hline & & BSE_SENSEX & EXCHANGE_RATE \\
\hline \multirow[t]{3}{*}{ BSE_SENSEX } & Pearson Correlation & 1 & $.424^{--}$ \\
\hline & Sig- (2-tailed) & & .000 \\
\hline & $\mathbf{N}$ & 108 & 108 \\
\hline \multirow[t]{3}{*}{ EXCHANGE_RATE } & Pearson Correlation & $-424^{-}$ & 1 \\
\hline & Sig. (2-tailed) & .000 & \\
\hline & $N$ & 108 & 108 \\
\hline
\end{tabular}

Table No.2: Correlation between BSE - Sensex and Exchange-Rate

\begin{tabular}{|c|c|c|c|c|}
\hline & & & BSE_SENSEX & EXCHANGE_RATE \\
\hline \multirow[t]{6}{*}{ Kendall's taub } & \multirow[t]{3}{*}{ BSE_SENSEX } & Correlation Coefficient & 1.000 & $275^{-1}$ \\
\hline & & Sig. (2-tailed) & - & .000 \\
\hline & & $N$ & 108 & 108 \\
\hline & \multirow[t]{3}{*}{ EXCHANGE_RATE } & Correlation Coefficient & $.275^{-}$ & 1.000 \\
\hline & & Sig. (2-tailed) & .000 & - \\
\hline & & $\mathrm{N}$ & 108 & 108 \\
\hline \multirow[t]{6}{*}{ Spearman's tho } & \multirow[t]{3}{*}{ BSE_SENSEX } & Correlation Coefficient & 1.000 & $.411^{-}$ \\
\hline & & Sig. (2-tailed) & - & .000 \\
\hline & & $\mathrm{N}$ & 108 & 108 \\
\hline & \multirow[t]{3}{*}{ EXCHANGE_RATE } & Correlation Coefficient & $.411^{-}$ & 1.000 \\
\hline & & Sig. (2-tailed) & .000 & - \\
\hline & & $\mathrm{N}$ & 108 & 108 \\
\hline
\end{tabular}


Graph No 1: BSE sensex and Exchange rate for study period (grphical Presentation)

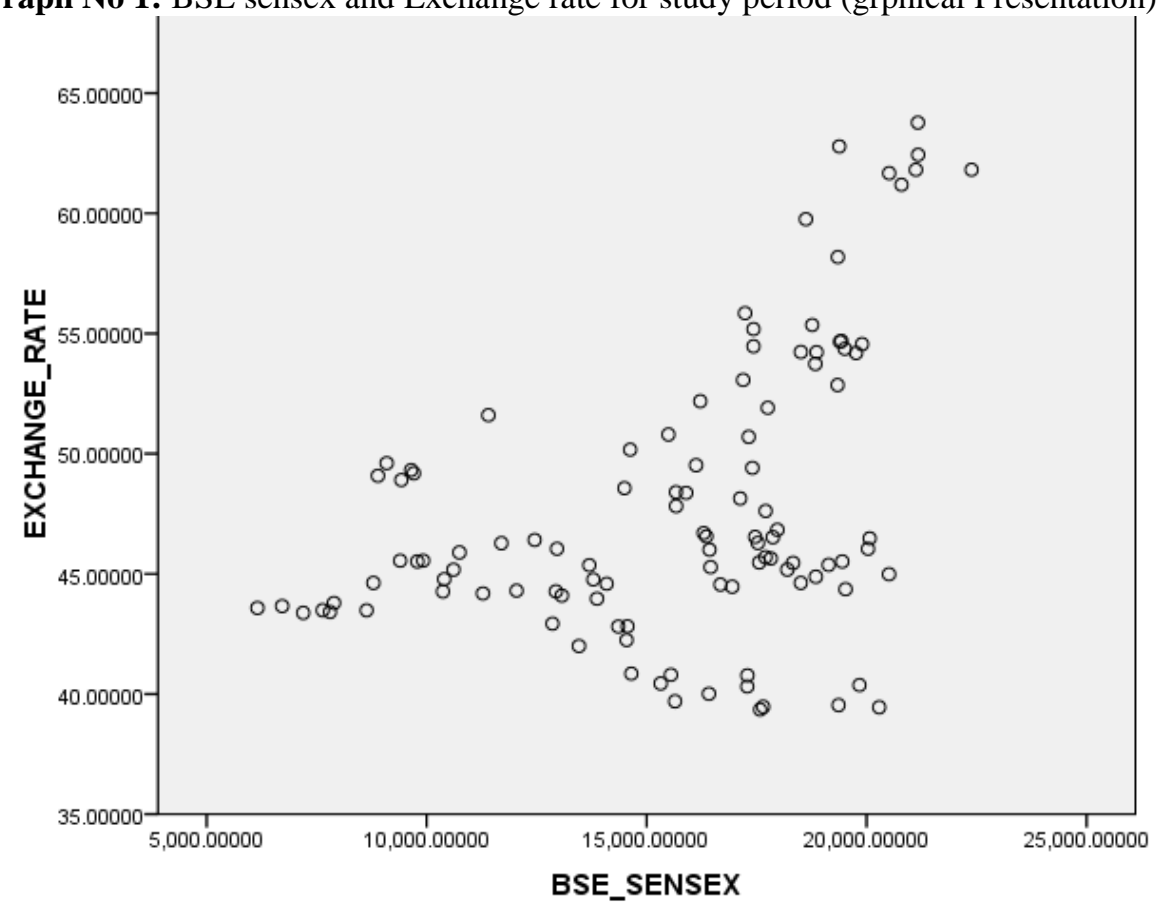

\section{Interpretation:}

From the above tables, it is clear that from the year 2005-2014, that the strength of association of Variables is very low $(r=0.408)$. The relationship between the two variables Exchange rates and BSE Sensex is very low and the relationship is weak. So finally we can find that there is no systematic pattern of lead or lag between the variables in this period.

Table No. 3: NSE - Nifty and Exchange-Rate

\begin{tabular}{|ll|c|c|}
\hline & & CNX_NIFTY & EXCHANGE_RATE \\
\hline CNX_NIFTY & Pearson Correlation & 1 & $.433^{\prime \prime}$ \\
& Sig. (2-tailed) & & .000 \\
& N & 108 & 108 \\
\hline EXCHANGE_RATE & Pearson Correlation & $.433^{-\prime}$ & 1 \\
& Sig. (2-tailed) & .000 & \\
& N & 108 & 108 \\
\hline
\end{tabular}

Table No. 4: Correlation between NSE - Nifty and Exchange-Rate

\begin{tabular}{|c|c|c|c|c|}
\hline & & & CNX_NIFTY & EXCHANGE_RATE \\
\hline \multirow[t]{6}{*}{ Kendall's taub } & CNX_NIFTY & Correlation Coefficient & 1.000 & $.288^{\prime \prime}$ \\
\hline & & Sig. (2-tailed) & . & .000 \\
\hline & & $\mathrm{N}$ & 108 & 108 \\
\hline & EXCHANGE_RATE & Correlation Coefficient & $.288^{\prime \prime}$ & 1.000 \\
\hline & & Sig. (2-tailed) & .000 & . \\
\hline & & $\mathrm{N}$ & 108 & 108 \\
\hline \multirow[t]{6}{*}{ Spearman's tho } & CNX_NIFTY & Correlation Coefficient & 1.000 & $.433^{\prime \prime}$ \\
\hline & & Sig. (2-tailed) & . & .000 \\
\hline & & $\mathrm{N}$ & 108 & 108 \\
\hline & EXCHANGE_RATE & Correlation Coefficient & $.433^{-1}$ & 1.000 \\
\hline & & Sig. (2-tailed) & .000 & . \\
\hline & & $\mathrm{N}$ & 108 & 108 \\
\hline
\end{tabular}




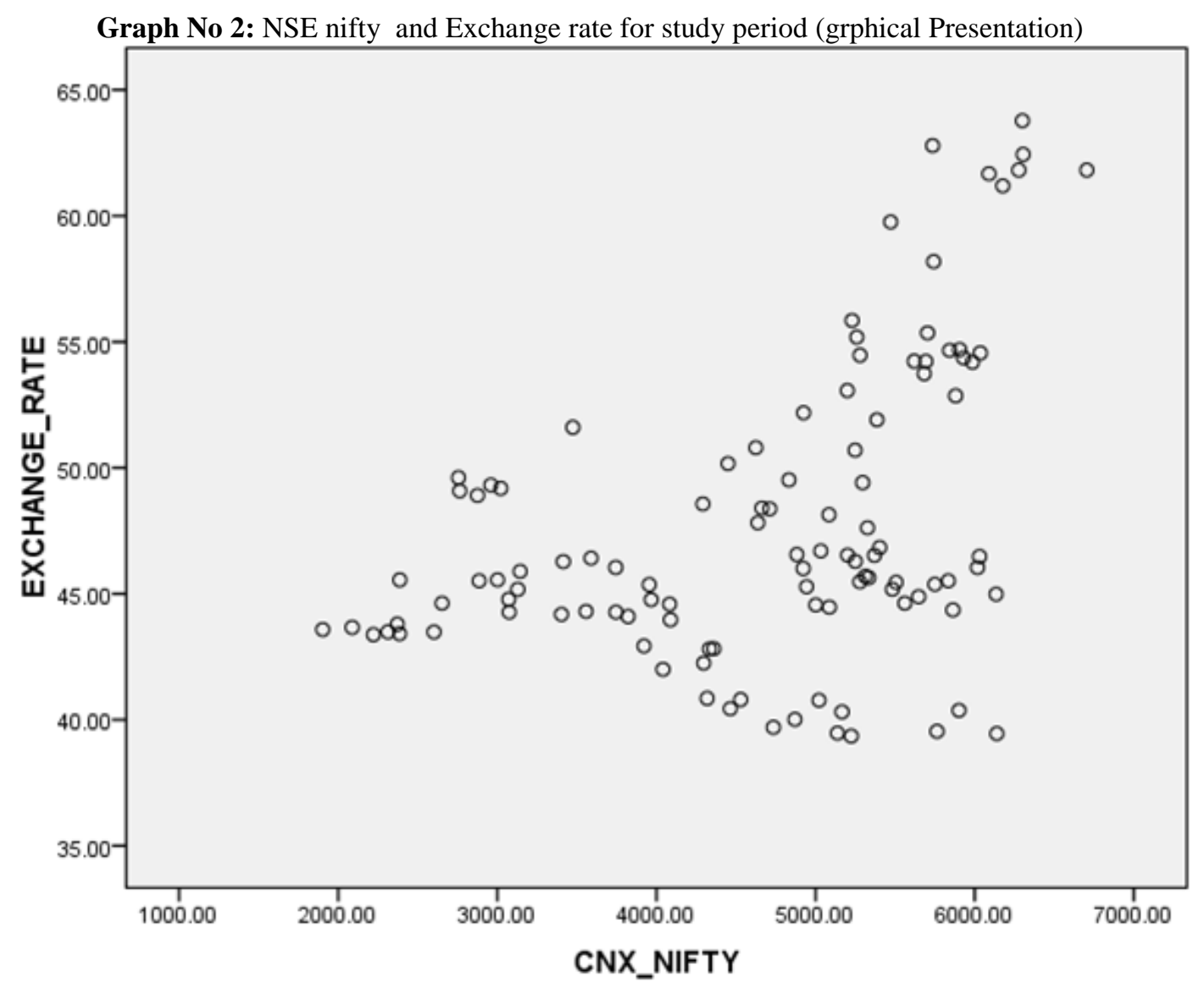

\section{Interpretation:}

From the above tables, it is clear that from the year 2005-2014, that the strength of association of variables is very low $(\mathrm{r}=0.433)$. The relationship between the two variables Exchange rates and NIFTY is very low and the relationship is weak. So finally we can find that there is no systematic pattern of lead or lag between the variables in this period.

Hence, we can reject the hypothesis that there is relationship between the exchange rate and stock indices and the two are affected by various factors in spite of the increasing integration between the two markets.

The following conclusions have been derived from our correlation analysis:-

- There is very less degree of positive correlation between stock indices and foreign exchange rates. Hence, we cannot reject the hypothesis that there is no relationship between the exchange rate and stock indices and the two are affected by various factors in spite of the increasing integration between the two markets.

\section{Findings:}

1. It can be said that because of using only a single variable, namely exchange rate, the impact on stock prices was not felt. If more of independent variables like interest rates, money supply etc. could be added, then possibly a very good relation could have been established.

2. In reality, stock prices and exchange rate are affected by a myriad of factors such as fiscal and monetary policy, interest rates, inflation, money supply, political factors, international events, fundamental performance, forex reserves, BOP, exchange control, etc.

3. The non-existence of relationship may also be because of Indian markets not yet being highly integrated or sensitive to the new information. Also the Indian companies comparatively may not be exposed to a lot of forex exposure, like companies in developed countries.

4. High volatility introduced in the exchange market due to floating rate regime nurtures the speculative activities, makes it difficult to pinpoint the precise effect of exchange rates on stock prices.

5. It is found that Indian stocks are highly sentiment driven and stocks of certain companies may change for no reason. There are few qualitative factors that influence stock prices like speculation and investor confidence level. 


\section{Suggestions:}

1. Exchange rate is complex variable that depends on a number of macroeconomic variables.

2. We should also consider the aggregate influence of Interest rate, IIP, money supply, central government policies etc. on exchange rate.

3. Since exchange rate is very active variables, the data can be taken on daily basis.

4. We can also directly link the inflow or outflow of FII and DII on the stock exchange value and consequently to exchange rate

5. We can also analyze the effect of major foreign stock exchange performances i.e. Dow Jones industrial average etc. on Indian stock exchange

6. We can also analyze the effect of market sentiments on stock performances and finally on exchange rate.

\section{Conclusion}

By using monthly data, we have examined relationship between stock prices and exchange rates in India. Our main concerns were to examine whether these links were affected by the existence of foreign exchange controls, floating rates and raising value of Rupee and raising indices in India.

The following conclusions have been derived from our analysis: There is no significant cause and effect relationship between the two variables. As the relationship occurred between the variables during different periods is because of chance factor and not because of cause factor. Thus the results provide the evidence for the presence goods market or portfolio approach. In the era of increasing integration in financial markets one should take sufficient care while implementing exchange rate policies. Furthermore, indications are that the existence of foreign exchange restrictions does not isolate the domestic capital markets. The general increase in international trade and the resultant increase in economic integration have also increased financial integration and reduced the benefit of international diversification.

\section{References}

[1] Relationship between Stock Market and Foreign Exchange Market in India: An Empirical Study by Deepti Gulati and Monika Kakhani, Pacific Business Review International Volume 5

[2] Dynamic Relationship between Stock Prices and Exchange Rates: Evidence from Three South Asian Countries by Md. Lutfur Rahman and Jashim Uddin, International Business Research

[3] An analytical study on the movement of nifty index and exchange rate by K. Malarvizhi, Dr. M.Jaya, International Journal of Marketing and Technology

[4] Impact of Inflation and Exchange Rate on Stock Market Performance in India by Dr. ChandraMohan and N.Chitradevi, Indian journal of applied research

[5] Dynamics of Stock Returns and Exchange Rates: Evidence from India by Mohammad Tanzeem Raza and S. Aravanan, Asia Pacific Journal of Applied Finance

[6] Ajayi and Mougoue (1996) "On the dynamic relationship between stock prices and exchange rate", Journal of Financial Research, $19,193-207$

[7] Kaminsky, Graciela, and Carmen M. Reinhart, 2000, On crises, contagion, and confusion, Journal of International Economics Vol. 51, No. 1, 145-168.

[8] Kurihara, Yutaka, 2006. "The Relationship between Exchange Rate and stock Prices during the Quantitative Easing Policy in Japan", International Journal of Business 11(4), pp.375- 386.

\section{Websites}

1. WwW.investopedia.com

2. www.nseindia.com

3. www.bseindia.com

4. www.exchangerate.com

5. www.bsi.com

6. www.sebi.gov.in 